\title{
INNOVATIVE Q-HRM PRACTICES IN IT ORGANIZATIONS
}

\author{
Dr. Rupa Rathee ${ }^{1}$, Ms. Renu Bhuntel ${ }^{2 *}$ \\ ${ }^{1}$ Associate Professor, DMS, DCRUST, Murthal, Haryana, India, ruparathee@gmail.com. \\ ${ }^{2}$ Research Scholar, DMS, DCRUST, Murthal, Haryana, India, bhuntelrenu101@gmail.com. \\ * Corresponding author
}

\begin{abstract}
There has been dramatic change in human resource management due to the advent of webbased applications and technologies. With the automation of basic HR functions through the implementation of e-HRM systems, the HR of an organizations appears to be a portal rather than a person. In India also companies are making using of e-HRM especially in the IT industry. Therefore, the present study was conducted to discuss the various innovative e-HRM practices used in IT organizations. The e-HRM practices include e-recruitment, e-training, $e$ learning, e-selection, e-performance management and e-compensation. Literature review was done in both the Indian context as well as foreign context. Data was collected from secondary sources which included websites of IT organizations (TCS, Infosys, HCL, Tech Mahindra and Wipro) in India. There are various e-HRM applications being used by each of these organizations for conducting their HR activities like Ultimatix by TCS, Sparsh by Infosys, Twingo by Tech Mahindra, My HCL by HCL and People Soft by Wipro.
\end{abstract}

Keywords: e-HRM, Practices, Innovations, Organization.

\section{INTRODUCTION}

An organization is made up of the four resources. In the other words it's $4 \mathrm{M}$ which includes: men, money, material and machinery. These all are the backbone of an organization. All these resources are available for developing the organization. Among these men or human resource are important making the efficient and effective use of the other resources so that the set goals are achieved. In the technological environment there is a need of the electronic human resource management which is also known as e-HRM. According to the Strohmeier (2007), "e-HRM is the planning, implementation and application of information technology for both networking and supporting at least two individual or collective actors in their shared performing of HR activities." According to Kavanagh et al. (2009) "e-HRM can be used for transactional activities (i.e. those that involve day-to-day transactions and record keeping); traditional HRM activities such as recruitment, selection, training, compensation and performance management; and transformational activities that add value to the organization." Bondarouk \& Ruel (2009) define e- HRM as, "an umbrella term covering all possible integration mechanisms and contents between HRM and information technologies, aiming at creating value within and across organizations for targeted employees and management". 
HR manager focuses on different activities for the development of the organization like the training and development, recruitment and selection, performance appraisal and many more. The role of HR is significant for the organizations. Nowadays all such work is done with the help of new technology. Because HR need new technology and innovative practice for the progress of the organization. Therefore, there is a need of the e-HRM, because it helps in erecruitment, e-training, e-learning, e-selection, e-performance management, e-compensation. It helps to improve the security of data, efficiency \& administration work, attendance registration, documentation system and reduce the burden of HR. The work of human resources continues to change with the help of e-HRM. In the multiple sector e-HRM techniques are used.

This study emphasizes on the e-HRM practices currently being used in the IT companies all over India. For studying the e-HRM practices, the top five IT companies of India currently listed in BSE and NSE stock exchange were considered. Due to limitations the researcher has confined to leading IT companies and discussed the e-HRM practices adopted by them. The success of the any organization depends on the effective practices being used for the development of the employees as well as the organization.

\section{REVIEW OF LITERATURE}

Swaroop (2012) studied how the e-HRM reduces the cost of an organization. He tried to find the benefits and advantages of e-HRM. The study was descriptive in nature. Data was collected from secondary sources. It was found that e-HRM is cost effective because the work is done with the help of e-HRM activities like applicant tracking, e-employee profile, e-training, erecruitment, e-selection, e-performance of management system. Later, Patil (2013) focused on the employee satisfaction and attitude towards e-HRM. He also focused on the challenges of e-HRM to IT employees. Descriptive study with a structured questionnaire was used. The eHRM technology supports the HR function through web technology-based channels. More than $75 \%$ employees were highly satisfied with secured database in e-HRM. 51\% employees were satisfied with easier communication among various departments. 50\% employee said e-HRM saved time. Lakshmi (2014) examined the e-HRM practices of the hospitals, suggested the strategies to implement e-HRM practices and analysed the feasibility of e-HRM. Total population was 2000 and selected sample was 150 using convenience sampling. Structured questionnaire through survey method was used for the data collection. Chi-square, correlation, weighted average mean were used for analysis. The study found that there was a high positive correlation between respondent's maintenance of record in physical work and easy to maintain e-data. Sinha and Mishra (2014) focused on identifying the extent to which different e-HRM tools were use in selected Indian organizations. They also explored the difference in usage pattern of e-HRM tools in context of private, public and manufacturing services. Structured questionnaire with 5-point scale, judgmental and convenience sampling were used for the data collection. The demographic structures of the employee were not in the favour of e-HRM implementation and this was only a perception-based study. Further, Sareen (2015) examined the degree of fulfilment of needs of end clients in an e-HRM framework. The e-HRM framework being utilized in chosen associations was segregated on the basis of its relationship 
with segment factors like age, sex, residency and work insight. Sample size of 182 was chosen for this research. A pre-tried survey was utilized to gather information from three associations in Delhi, Gurgaon, Noida. The investigation found that work insight and age have a critical connection between level of fulfilment towards e-HRM.

Ruel et al. (2004) studied the extent of change in worker relationship in organizations with the arranged utilization of e-HRM and how this change happens. Five huge organizations were chosen for information assortment which included Dow Chemicals, ABN AMRO, Ford Motor Company, IBM and Belgacom. Case study, case selection, observation techniques and interview method were used. The examination found that representatives and line chiefs outlook should be transformed: they need to acknowledge the value of electronic HR instruments. They for the most part feel that they come up short on the reality expected to work unobtrusively and mindfully with electronic HR apparatuses. Later on, Ruel et al. (2006) studied the assessment of e-HRM applications that determine the contribution of strategic and technical HRM effectiveness. The researchers used quantitative study in which online questionnaire were used based on five-point Likert scale. The study found that assessment of e-HRM applications influence HRM technical \& strategic effectiveness and positive effect on HRM. Voermans \& Veldhoven (2006) focused on the research on attitude towards e-HRM. An examination model was figured dependent on the two hypotheses from correlative exploration zone: Davis' innovation acknowledgment model and Ulrich's model on HR jobs. Online survey was used to gather information from 99 chiefs and 257 representatives inside Philips (Electronics). Factor analysis (principal components, varimax) was used. It was discovered that distinctions in current IT frameworks, just as the favoured HR jobs were vital accomplice (high inclination) and representative hero (low inclination) identified with inspirational mentality towards e-HRM frameworks. For chiefs, client support was additionally discovered to be an indicator of an inspirational mentality towards e-HRM. Barrett \& Oborn (2013) developed a better electronic human resources system and themes of the e-HRM practices. Empirical study was conducted. The study found that HR can develop innovative practice and service approach into the organization.

Stone \& Dulebohn (2013) examined the how HR scholars may perceive that HRMIS and eHRM. Empirical study was conducted for the research. The study found that strategic considerations influence decision-making on e-HRM applications. Panneerselvam (2017) analysed the impact of implementing e-HRM in India, e-HRM growth and their practices in the organization. The author had given information about e-HRM usage and the work simplification in the organization. Secondary data was collected for the research. The study found that Indian administration is different from the European administration in the case of the technology and the usage of e-HRM was less in the Indian organization. Also, it was found that managers and employees did not have the mind set for the development of the e-HRM implementation. Even the other organization members were not aware about the e-HRM implementation. Rahman and Hosain (2021) aimed to ascertain the relationship between organizational sustainability and e-HRM practices. Both primary and secondary data was used for the study. Data was collected from 387 respondents using structured questionnaire. The data was analysed using correlation and regression analysis applied through SPSS. It was found 
that there was significant and positive correlation between organizational sustainability and eHRM practices.

\section{OBJECTIVE OF THE STUDY}

To explore the various innovative e-HRM practices used in IT organizations.

\section{DETAILED DESCRIPTION OF PRACTICES OF E-HRM}

- e-recruitment: e-recruitment means recruiting a person online who is suitable for the job. "erecruiting is using the internet to recruit through corporate websites, specialized websites or online advertisement", according to Galanaki (2002). e-recruitment helps in the applicant ranking with the help of the different corporate sites like nakuri.com, monster.com, shine.com and many other corporate sites such like these. It also helps in the new and innovative idea for e-recruitment in the organization. Tyagi (2012) suggested that candidate can apply online on corporate websites, adding themselves to the company's database. Nasreem et al. (2016) found that majority of the respondent preferred e-recruitment advantages of quality of applicants, wider applicant's choice, time and cost reduction.

- e-selection: e-selection follows the e-recruitment. e-selection involves choosing the best out of e-recruitment. e-selection comprises of two methods, one is ability test and other is personality test. It is the process of hiring the employees in the organization with different mediums like online test, interview, reference checks and final interview.

- e-training: "Training usually refers to the teaching operational or technical employees how to do the job for which they were hired" as defined by Griffin (n.d.). e-training helps in the knowledge, skills and ability of the employees. In the organization with the help of the different e-training techniques like online coaching, smart classes, mentoring etc. that improve the employee knowledge and skills. It increases the employee satisfaction level. The e-training programs increases the talent and capability that improves morale and productivity of employees (Sheeba, 2011). Training is "the art of intervention to improve organization's service quality in stiff competition by improvement in technical skills of employees" (Manju and Suresh 2011).

- e-learning: "The use of internet and digital technologies to create experiences that educate fellow human beings" (Horton, 2001). e-learning help in increasing the performance and productivity of the employees because employees are always looking for the new opportunities and idea for their development. It saves the time of the employees with less effort. It is cost effective in the nature. Strother (2002) focused on the cost-effective ways to deliver e-training/ e-learning programs to their employees. Dublin (2004) suggested that e-learning efforts were useful for the learner's needs and organization's expectations.

- e-compensation: e-compensation services are developed by organizations through its intranet and internet through which all employees are able to reach it from anywhere. It includes the direct and indirect pay of the employees like salary, wages and other benefits for the employees. 
e-compensation helps in the employee attendance record, leave record, generate pay slip and annual returns. e-compensation frameworks are additionally used to convey information about advantages alternatives to representatives and offer them the chance to choose advantage plans online. (Gueutal and Falbe, 2005). e-remuneration frameworks likewise enable directors to create spending plans, demonstrate the effect of incentive frameworks and guarantee the decency of compensation designation choices (Marler et al., 2006).

- e-performance management: e-performance management is creating a work environment where the employees are enabled to perform to the best of their abilities. In the organization eperformance management helps to monitor the performance of the employees and capture the data for measurement of performance elements. Information is kept secure in online performance management rather than being placed in employees' files in offices (Payne et al., 2009).

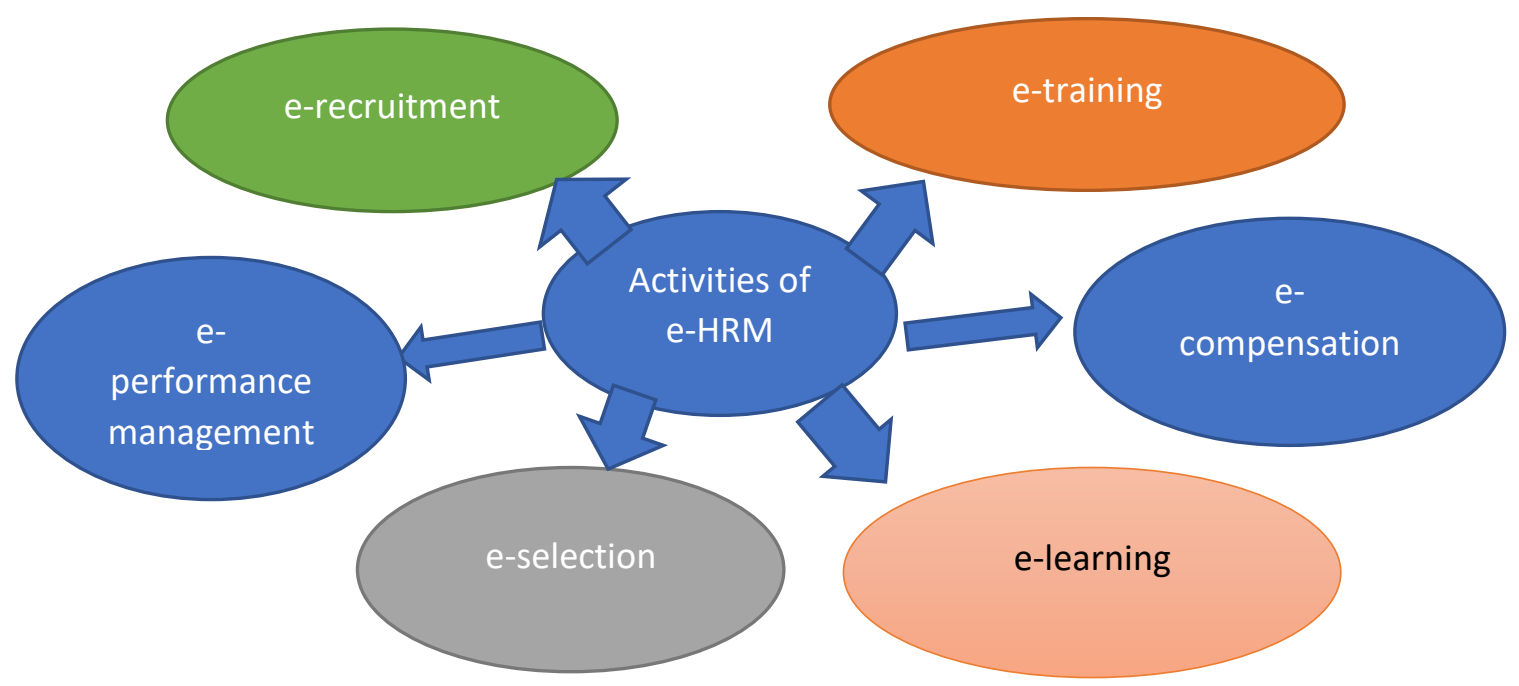

Figure 1 Innovative Practices of e-HRM

\section{COMPANIES THAT ARE USING INNOVATIVE E-HRM PRACTICES IN INDIAN CONTEXT}

\section{TCS}

TCS company uses the software Ultimatix for their employees. In the various department of the TCS company like the Finance, HR, Engineering, Research \& Development and many more; people work on this software. In this all-application software in which employee services, project delivery \& sales, HR talent \& delivery, finance, learning \& collaboration and utilities \& infrastructure were used. For the different purposes according to the employee requirement, the software is used. The Center of Excellence for Accessibility deals with IT answers for in an unexpected way how expert people, helping their reconciliation into the labor force. TCS additionally runs different activities to assist representatives with developing their vocations, like CareerHub, a stage that furnishes them with coaching administrations. They likewise run Inspire, a particular program that gives quick track profession movement to high- 
possible representatives. Intermittent initiative surveys help keep a sound progression pipeline (tcs.com).

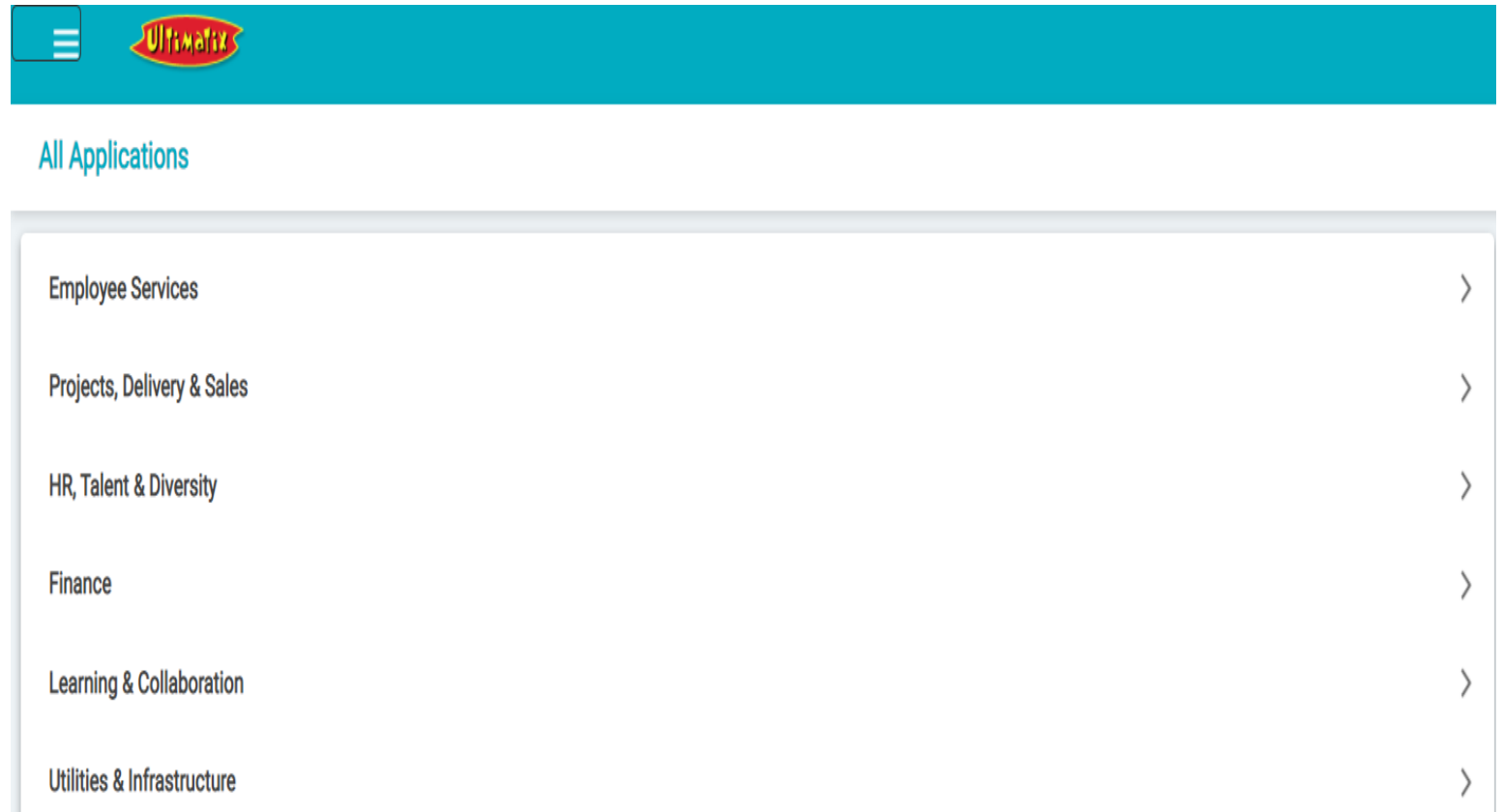

Figure 2 TCS (source: TCS COMPANY)

The figure 3 shows the brief descrption about the employees self services that TCS provide to their employees. These self services are like: Digital Profile, Employee Concerns, Exciting opportunities, My Allocation \& Utilization, My Documents, My Notices, Personal Records and Timesheet entry. This includes the database in which all the details of the employees exists.

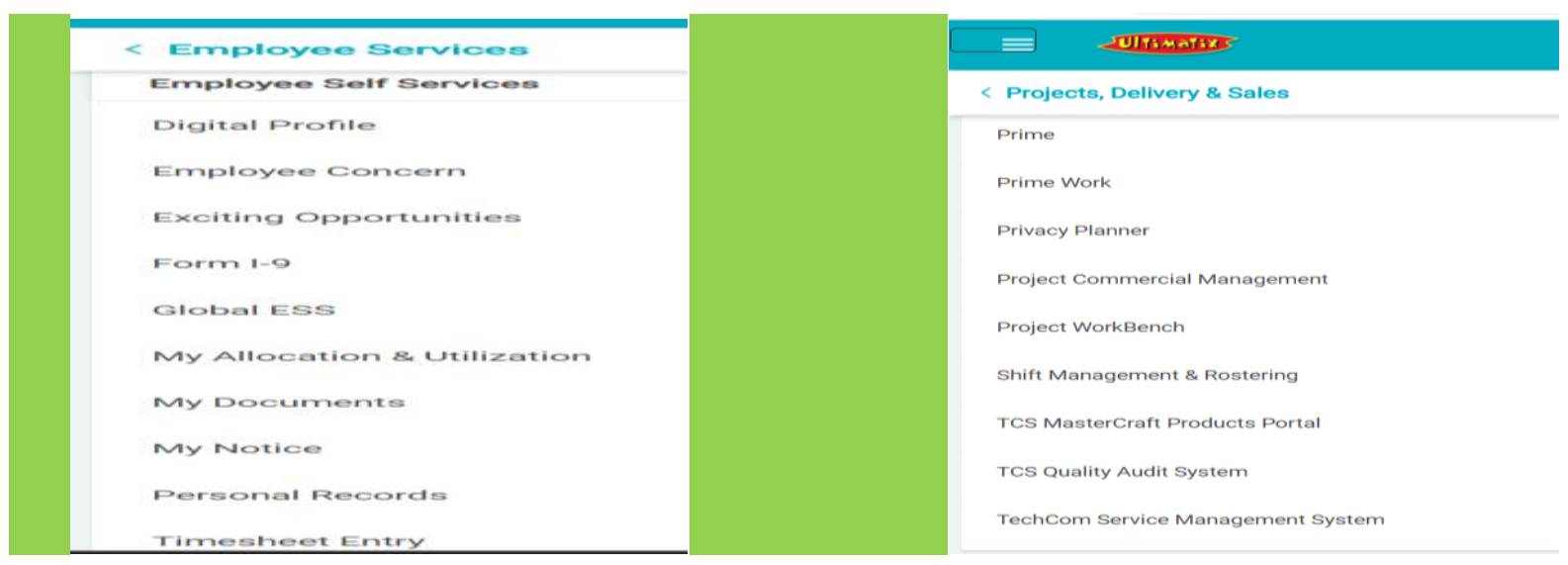

Figure 3 Employee services (Source: TCS) 


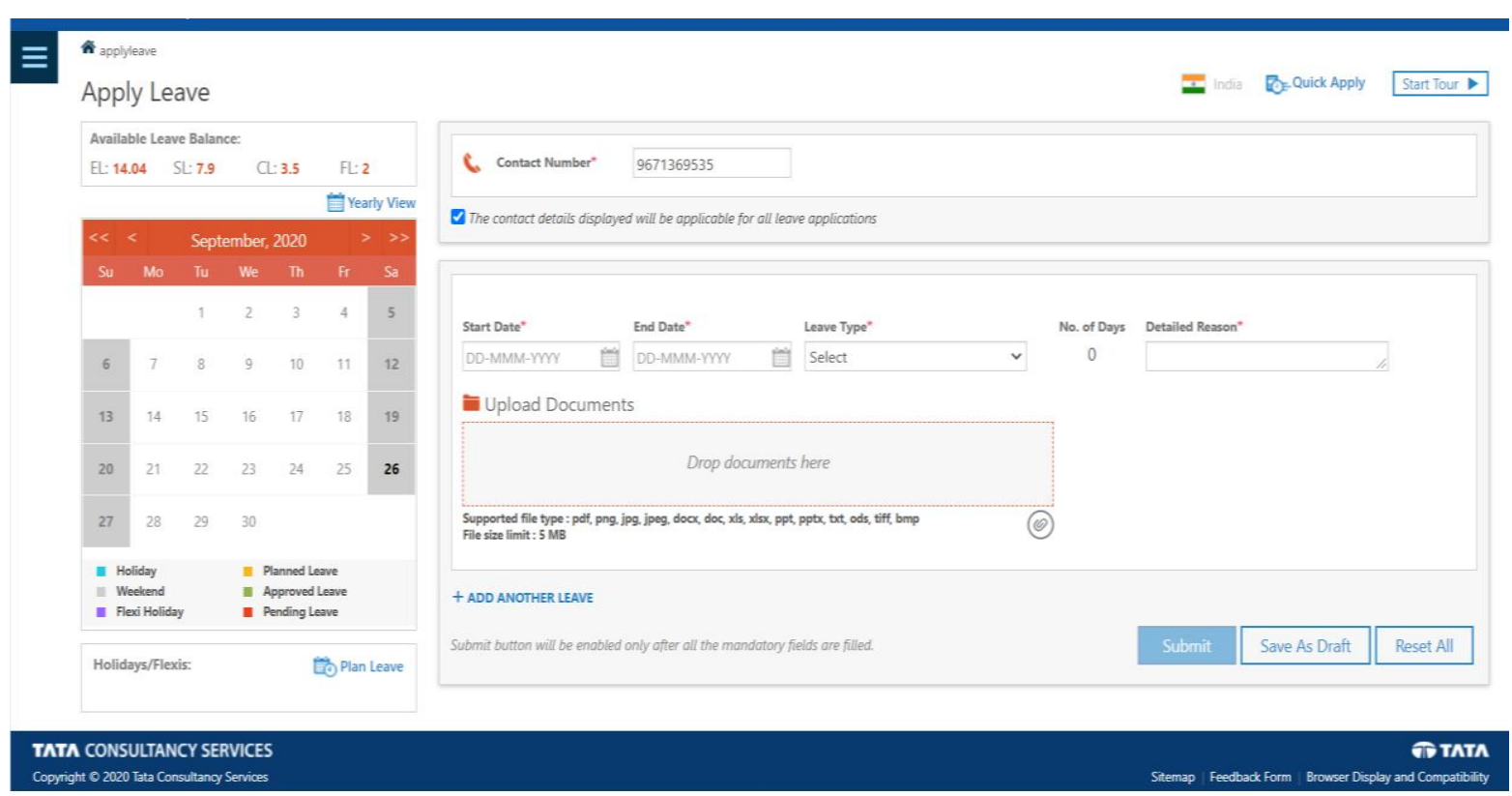

Figure 4 Leave Format (Source: TCS)

This figure 4 shows how TCS employee apply their leaves. In this manner this is related to the compensation management system of the employees. The above figure shows the employee payslip that is related to the personal details of the employees. This data is the TCS company employee's data. They also have a calendar which shows the daily basis event, activities and the programs schedule for the employees. Apart from these there are some mobile applications in the TCS company that are being used as part of e-HRM services.

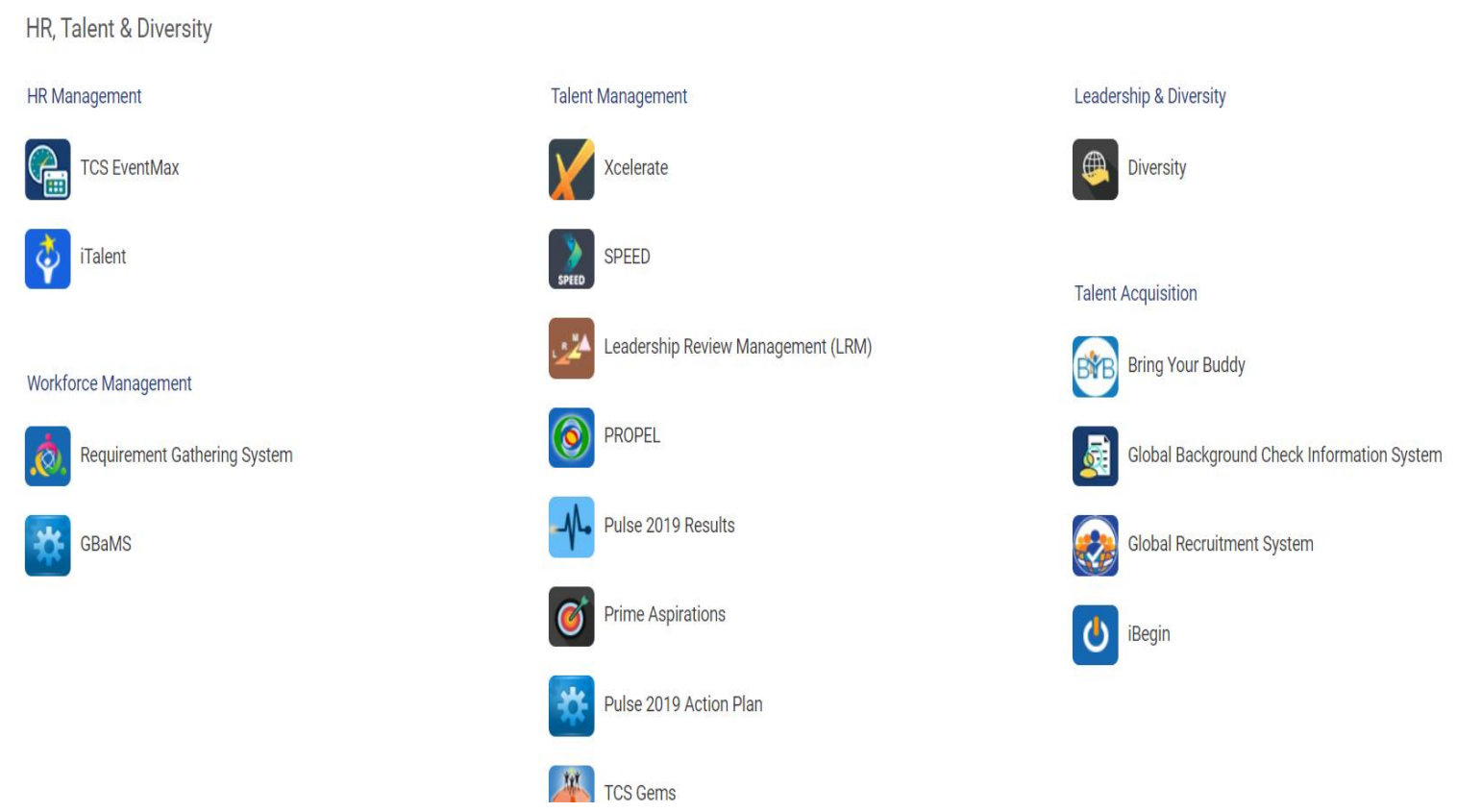

Figure 5 HR Talent (Source: TCS) 
This figure 5 shows the HR, talent \& diversity applications. In which under the HR management TCS has EventMax and iTalent.

In the workforce management there is requirement of gathering system \& GBaMS.

In the talent management Xcelerate, SPEED, Leadership Review Management (LRM), PROPEL, Pulse 2019 Results, Prime Applications, Pulse 2019 Action Plan, TCS Gems are some of the applications being used. There is also an application for the system security assurance.

\section{HCL}

HCL provides the facility of online training, collaborative learning, certification programs, instructor-led and on demand training for their employees. HCL company's board of director thinks creating a learning environment for the employees of organization for the new idea and innovative practices is of utmost importance. MYHCL software is used in HCL organization for the development of the employees. HCL's Smart Service Desk - is an application accessible to all workers on their work areas. For any issue and exchange, the workers don't need to hurry to HR or money or hit them up, they can just open a ticket in the Smart Service Desk and the cycle begins its own. The goal of such a framework is to tell the senior administration that they must take care of worker gives quick so the representatives are allowed to tackle their work. The utilization of IT has likewise assisted HCL with lessening the part of the HR office in sending of individuals. The framework consequently finds individuals accessible for a specific sort of work and advises the line supervisors. HCL Comnet, for example, has an uncommon site for new participants. The New Comnetian site, a site with all-in-one resource for all data that the students need to get drafted in Comnet and comprises oneself learning part of the acceptance program. Another of HCL's imaginative correspondence activities is the month-tomonth e-zines, which break down and pronounce the presentation of all operational groups each month (Majumdar, 2013).

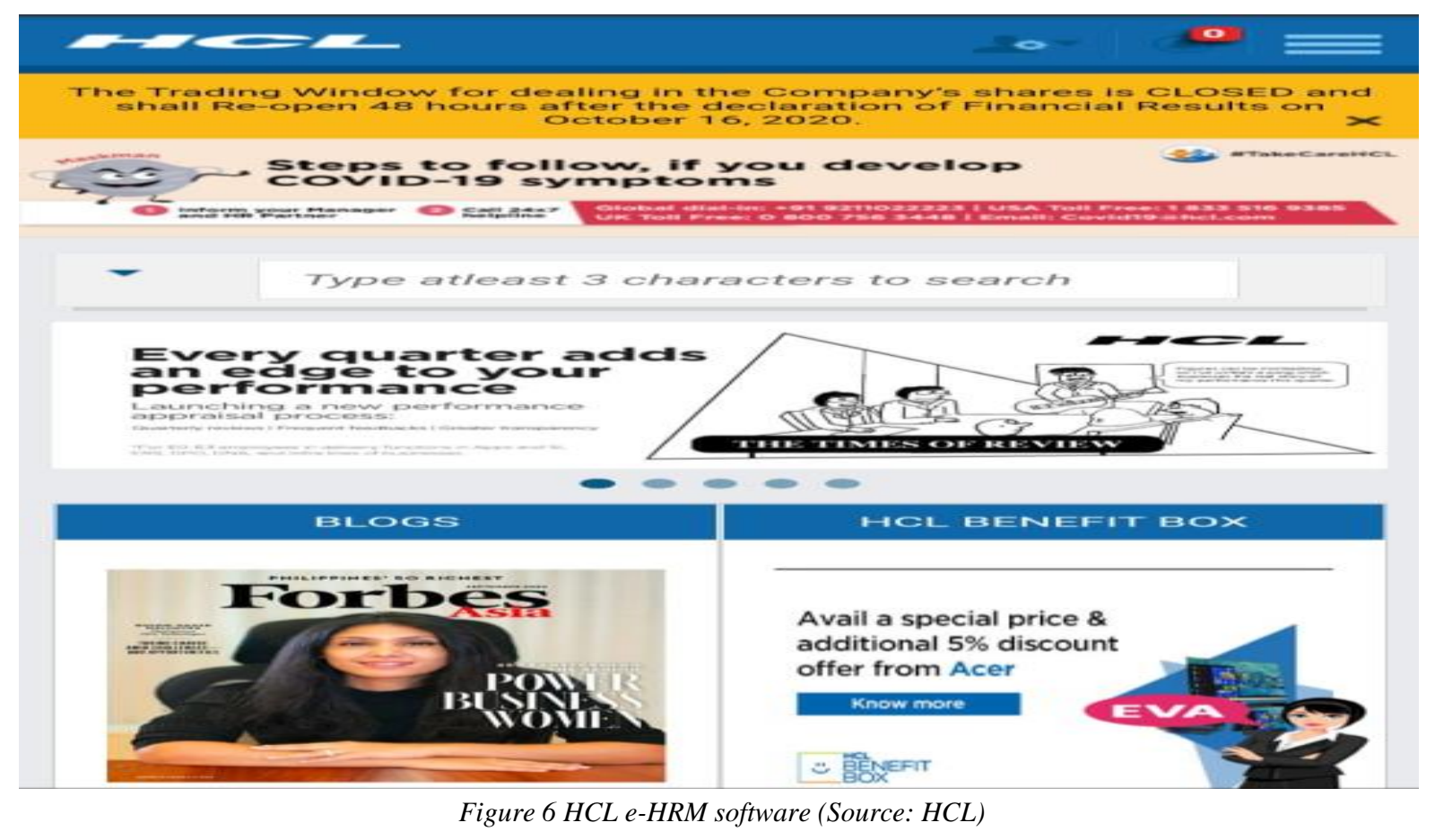


In the HCL company my HCL software is being used. This is open window of the HCL.

\section{: My Performance}

Dashboard

Review Period: 2019-20

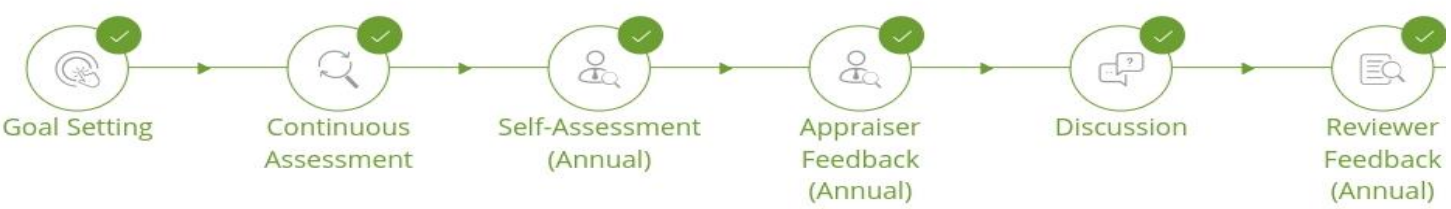

Figure 7 My performance (Source: $H C L$ )

For the performance appraisal in HCL company there is "My performance" named software which is used. Where the main focus on the goal setting, continuous assessment, selfassessment (annual), appraise feedback (annual), discussion and reviewer feedback (annual). On this basis the performance of the HCL employee is calculated.

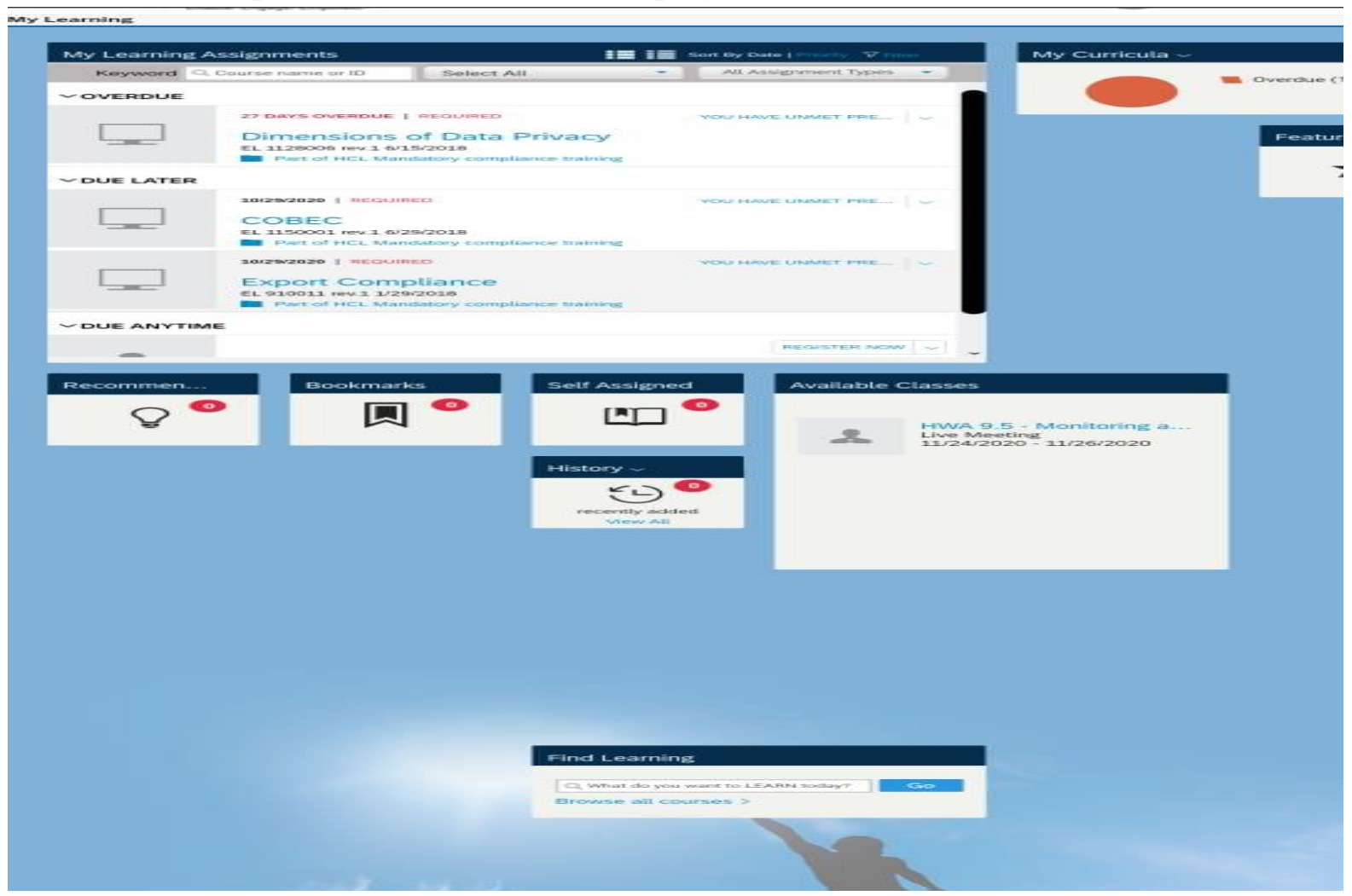

Figure 8 My Learning software (Source: HCL)

For the training and learning in HCL company there is "my learning" software which is being used. In which all the details of the training and learning assignment of the employees. For the training "isuccess" software is used in HCL. 


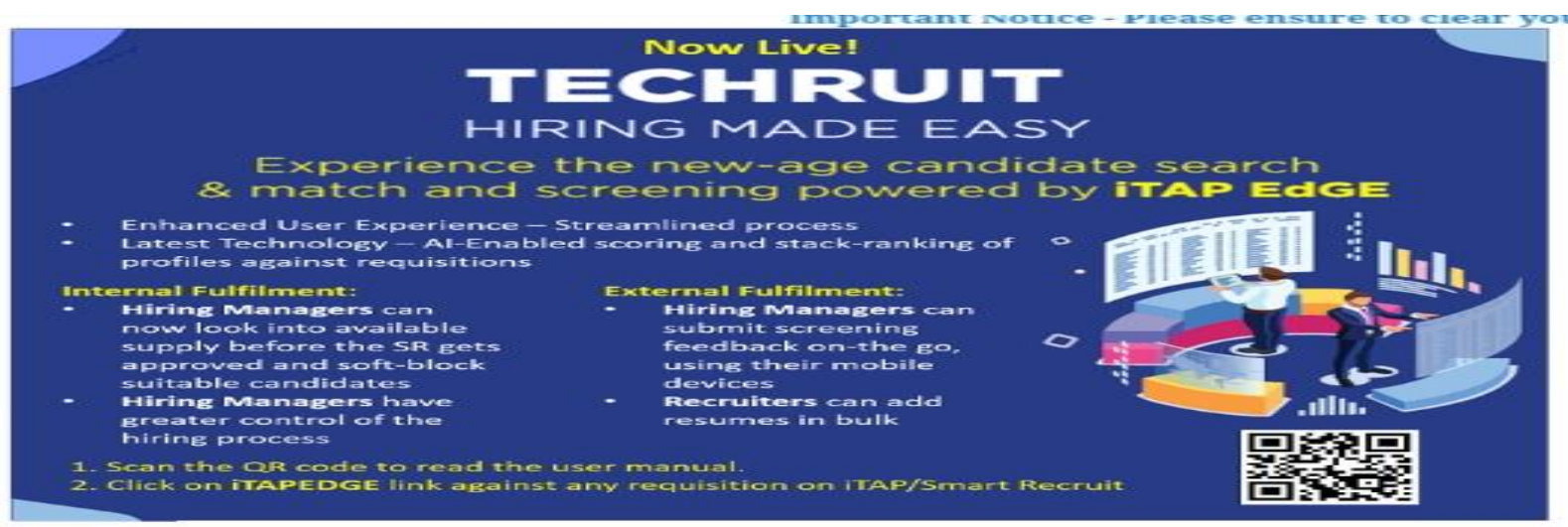

Figure 9 Techruit (Source: HCL)

For the e-recruitment in the HCL company there is "smart recruit" software that is being used. This software is used for hiring the employees.

\section{INFOSYS}

Infosys Company also provides Online Training facility for their employees. Curiosity levels among Infosys employee has been continuously changing while using e-training and development programs. Everyone is keen to know the procedure and process of the Online Training and its implications on the in-campus training to be held at Infosys Mysore. Sparsh software is used in Infosys for the development of the employees. Infosys also uses Recruitment Management System (RMS) developed by Blueshift, an online solution provider based in Chennai, India. Blueshift is built on a dot NET platform and consisted of different modules for candidates who applied directly, for employee referrals, for staffing agencies which submitted the profile of suitable candidates and for applications submitted by campus placement coordinators. Infosys additionally underlines upon the board and authority advancement program as and when required and obliges the prerequisites of the executive's improvement for its senior representatives and chiefs. The newcomers are prepared at the Global Education Center (GEC) in Mysore, which has world - class preparing offices and the ability to prepare in excess of 4,500 representatives all at once (Sree Rajani, 2016).

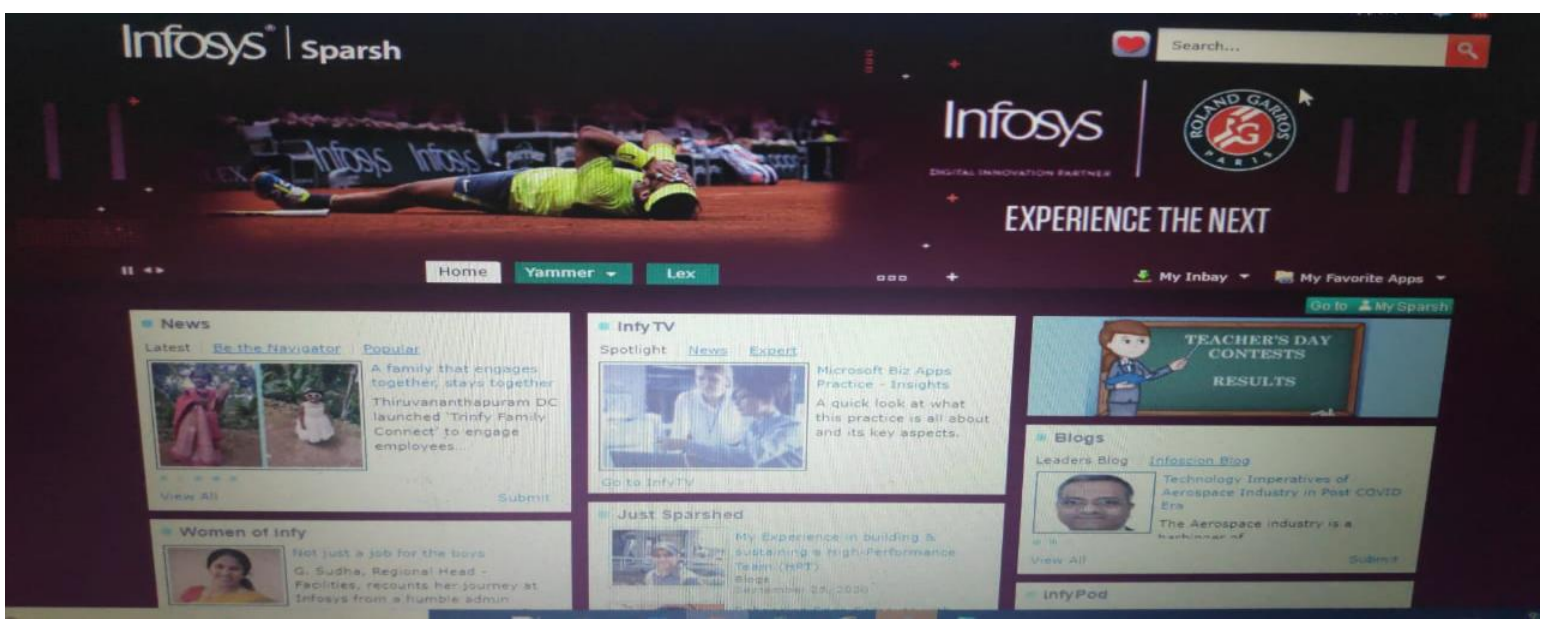

Figure 10 Sparsh Software (Source: Infosys) 
In Infosys company Sparsh software is being using for their employees.

For recruitment and selection Infosys uses Recruitment Management System (RMS) developed by Blueshift, an online solution provider based in Chennai, India. Blueshift is built on a dot NET platform and consists of different modules for candidates who applied directly, for employee referrals, for staffing agencies which submitted the profile of suitable candidates and for applications submitted by campus placement coordinators. Infosys recruits experienced personnel for positions such as domain experts, domain consultants, personnel in the consulting area and technical architects. In foreign markets, most of the sales personnel and client servicing personnel are recruited locally. According to Hema Ravichander (Ravichander), former Global Head (HR), Infosys, "About $41 \%$ of the client facing team is non- Indian and approximately $2 \%$ of Infoscians are non-Indians.

\section{Infosys training and development}

Worker improvement and preparing at Infosys is a ceaseless interaction. At the point when recruited, representatives quickly go through acceptance and preparing program. These projects chiefly expect to underline on preparing these newcomers on new cycles and innovations and arrange them with the association's way of life and moral practices. As they arrive at higher proficiency and execution levels, they are additionally prepared on project the executives' instructional courses with the goal that they could create capabilities for autonomously taking care of tasks and tasks for the association's customers. Infosys likewise underlines upon the executives and authority improvement program as and when required and takes into account the prerequisites of the board advancement for its senior representatives and directors. The newcomers are prepared at the Global Education Center (GEC) in Mysore, which has world - class preparing offices and the ability to prepare in excess of 4,500 representatives all at once.

\section{TECH MAHINDRA}

Tech Mahindra company works on TWINGO software. In this IT company this software is used for the different purpose like e-recruitment, e-training, e-compensation and e-performance management. Tech Mahindra Ltd. is a main supplier of computerized change, counseling and business re-designing administrations. They presented K2, the main Human Resource (HR) Humanoid for its Noida Special Economic Zone Campus in Uttar Pradesh, India in 2019. K2 use cutting edge Artificial Intelligence innovation and starts discussion with no requirement for awaken orders. Remembering the necessities of the particularly abled, K2 can react to inquiries with text shown alongside Speech. K2 can address general and explicit HR-related representative questions just as handle individual solicitations for activities like giving payslip, tax documents and so forth and empowers the HR group to zero in on other significant zones for worker advancement (techmahindra.com). Tech Mahindra company uses TWINGO software for their employees. Below the image of the Twingo software which indicates that TechM web \& information on the go. 


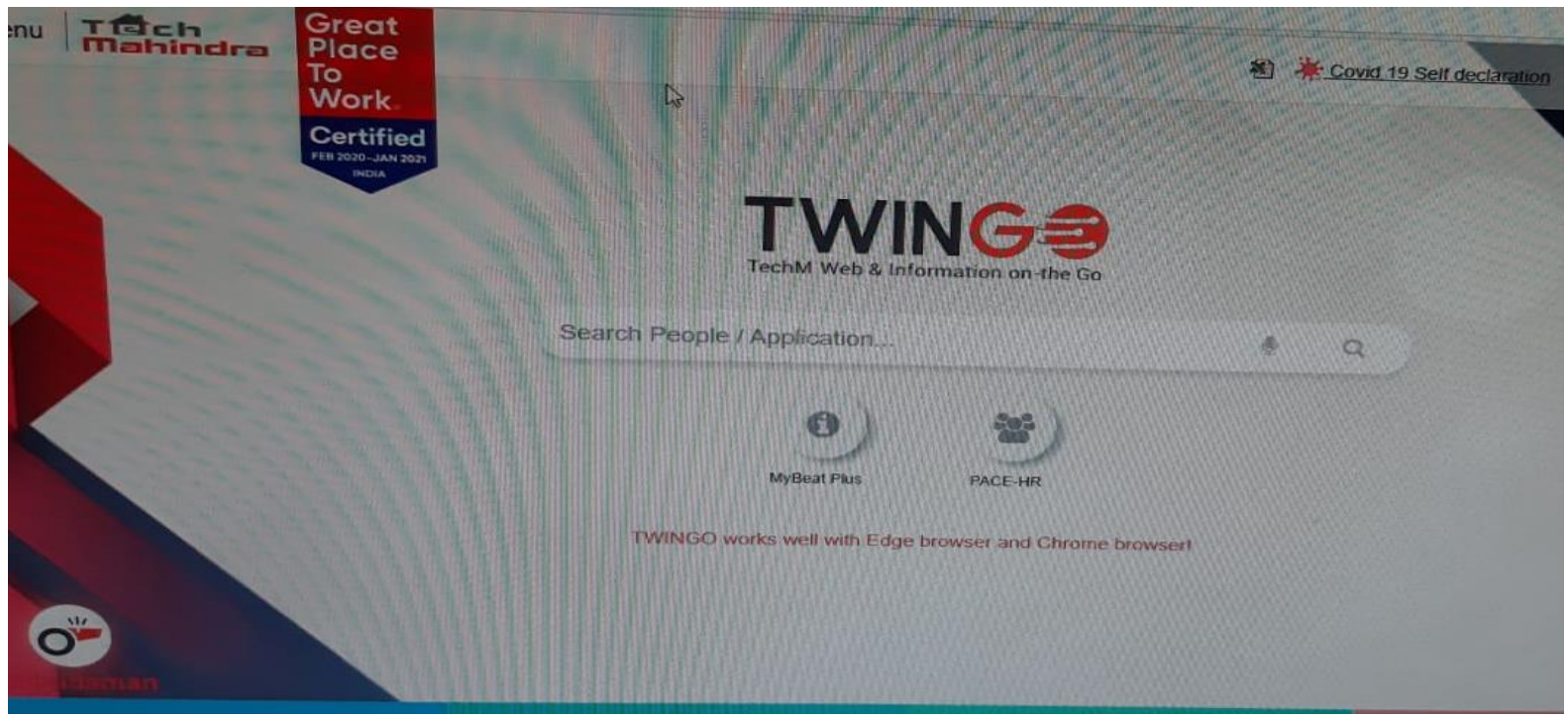

Figure 11 Twingo (Source: Tech Mahindra)

This image shows the application programs that the company uses. For example, PACE, Human Resource, Quality (QWAY), Information security, CIO, Finance, The Hub, TIM, Info \& Communication, Sales (Authorised Access), Global Alliances.

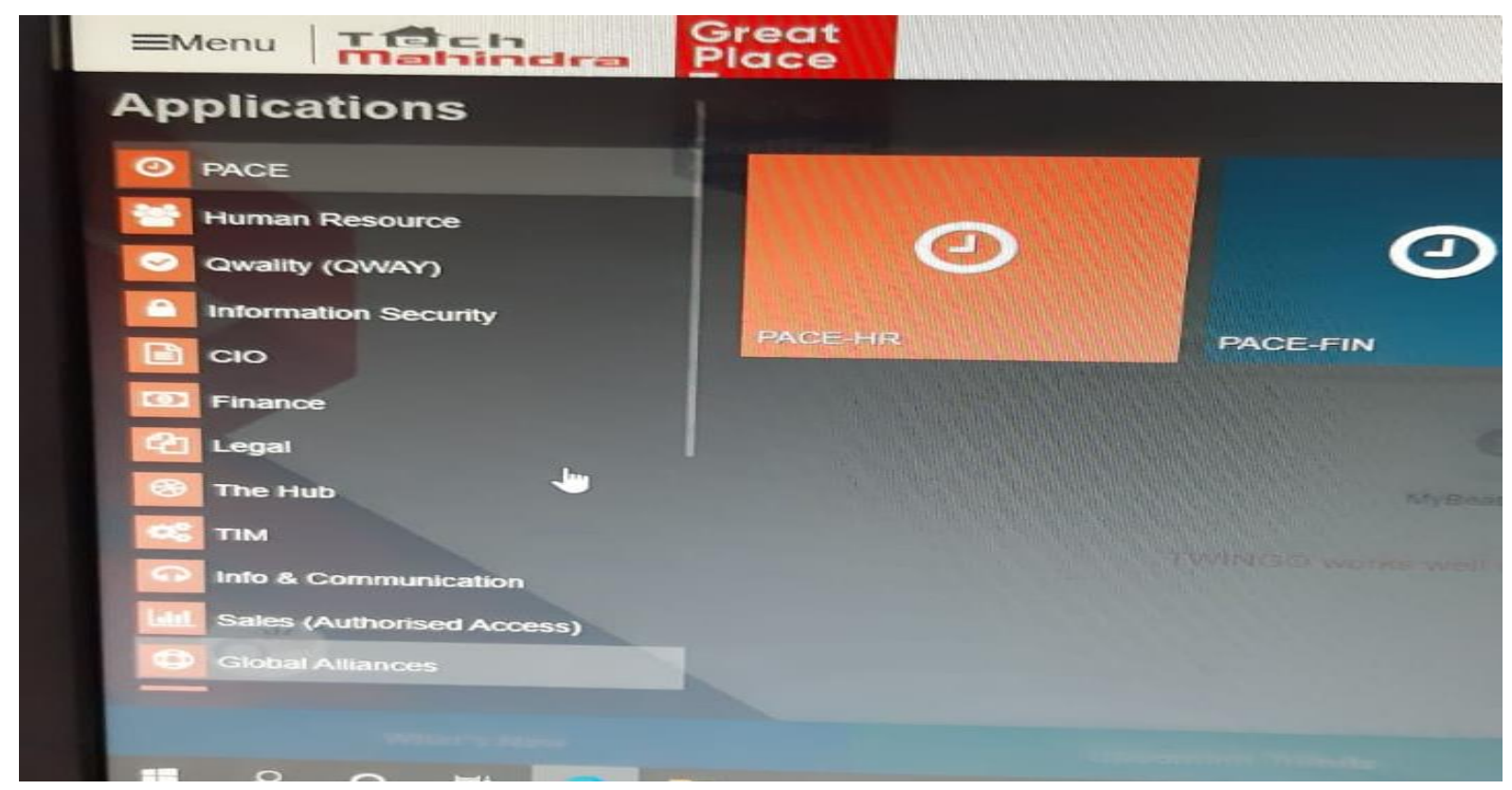

Figure 12 Applications (Source: Tech Mahindra)

This image shows the other programs list that are used in the Tech Mahindra. For example, Business intelligence, Middle Office, Training, Corporate Services (CS), Corporate Shared Services, Corporate communications, RMG, BPS. 


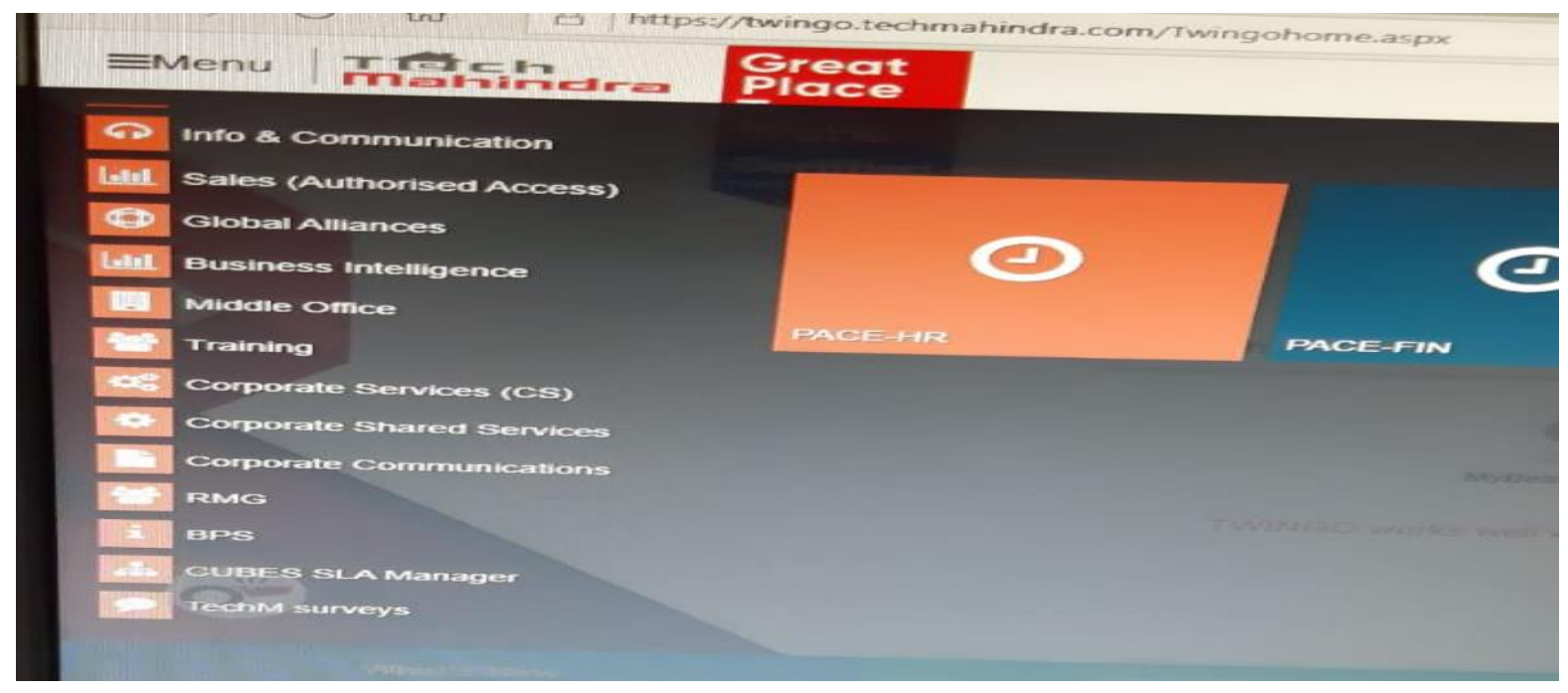

Figure 13 Applications (Source: Tech Mahindra)

This is the human resource image in which it shows the core HR, Career and Payroll. In the payroll My Time, PF Helpdesk, Time Tracker and Variable pay used.

In this image these are the software that used for the training learning programs like: DEXTGet Ahead, My Tube, Library, future skills and NAD.

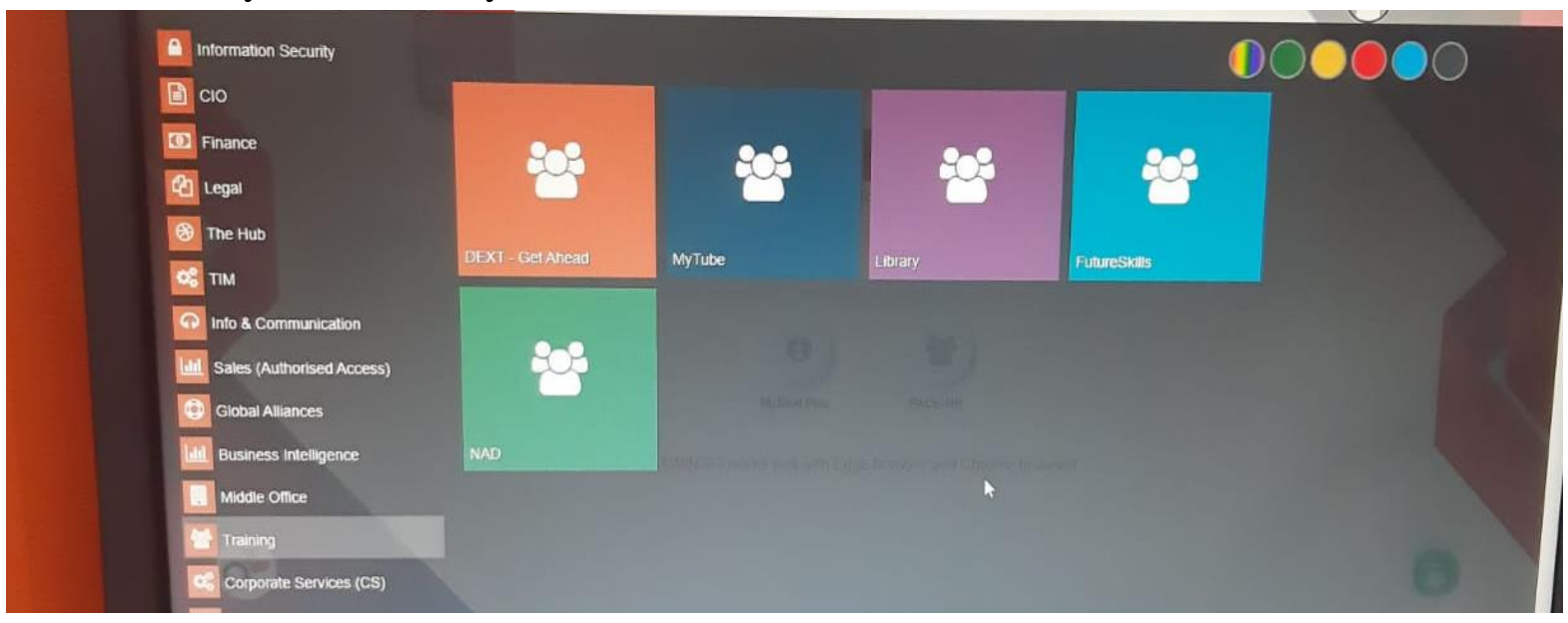

Figure 14 Applications (Source: Tech Mahindra)

This image shows the e-HRM platforms images like e-recruitment on the NTR portal and the other options like iperforms and CARE. On the other hand, compensation and rewards software show how they are calculated.

\section{WIPRO}

WIPRO company is working on PeopleSoft software which is used for the development of their employees. Wipro banded together with Oracle for most amazing aspect breed HR stage arrangements. Wipro likewise chose The Hackett Group, a worldwide vital warning firm, to give exact information, best practices and top-notch execution bits of knowledge on the improvement of its creative packaged arrangement stage. It conveys this exceptional worth blend by incorporating a-list execution experiences and benchmarking measurements from 
Hackett with Oracle PeopleSoft human resources the board and Wipro's universally advanced HR conveyance ability (wipro.com).
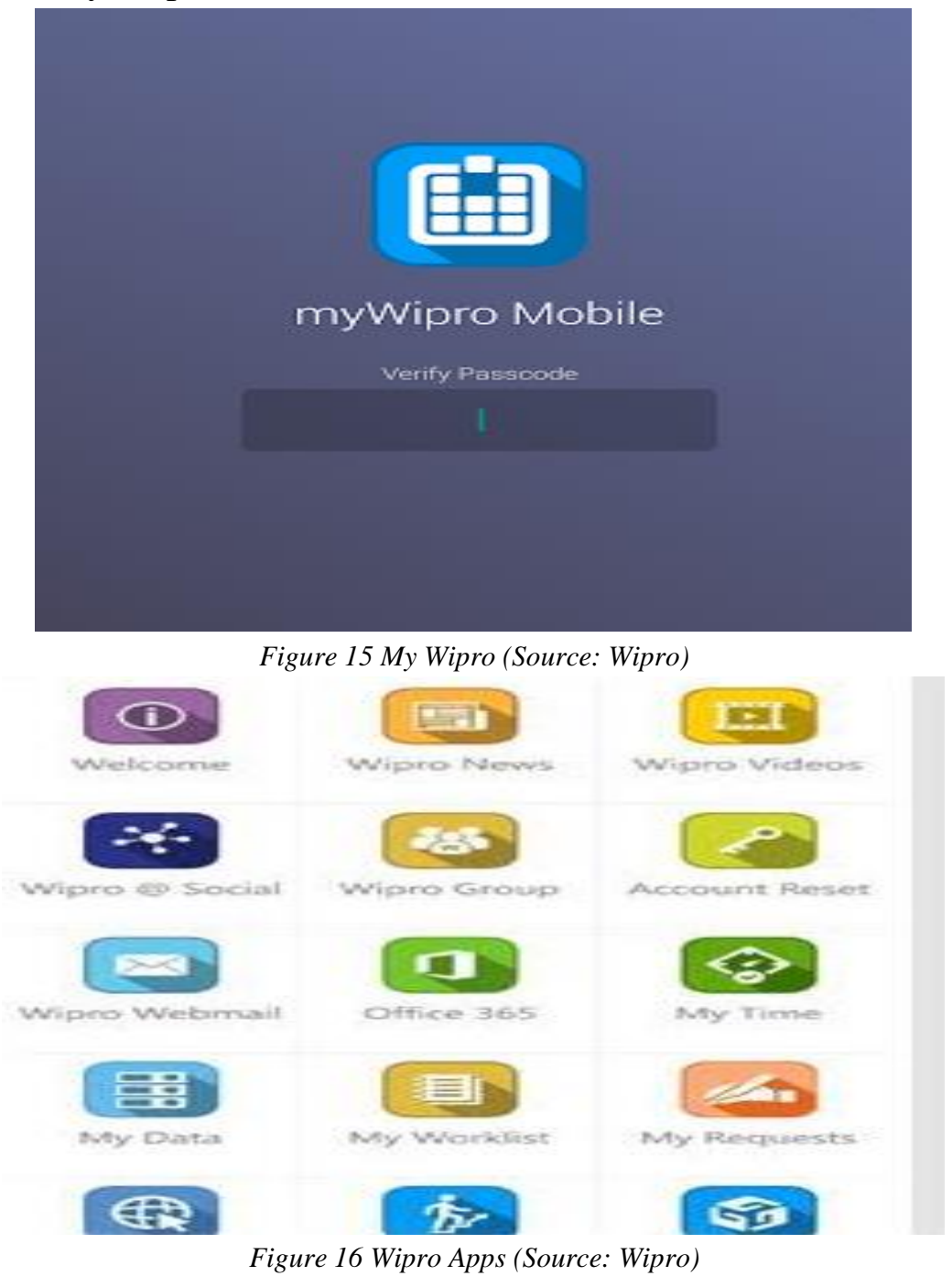

\section{CONCLUSION}

The objective of this study was to explore the various innovative e-HRM Practices being used by IT organizations in Indian context. Main focus of this objective was to explore the uses of the e-HRM Practices in IT sector. The present study focused on the top five IT companies that are listed in BSE and NSE stock exchange. These companies use different e-HRM practices like e-recruitment, e-selection, e-training, e-learning, e-compensation, e-performance appraisal. For example, TCS company uses the software Ultimatix for their employees. In the various department of the TCS company like the FINANCE, HR, Engineering, Development and many more, the employees work on this software. For example, HCL company uses MYHCL software for the development of the employees. For example, Infosys Sparsh software is used in Infosys for the development of the employees. Tech Mahindra company works on the TWINGO software. WIPRO company works on PeopleSoft software for the development of their employees. The use of such innovative e-HRM practices has made the work of HR department smooth and efficient. 


\section{SUGGESTIONS}

- e-HRM has become an inseparable part of the functioning of almost all the large business players. Therefore, too much dependency on the online system requires good backup systems which keep all data and information intact.

- e-HRM systems must be flexible so that new users may not find it difficult to use.

- e-HRM facility provides interactive learning environment for the organization and employees especially during adverse situations like the Covid-19 time period.

\section{IMPLICATIONS}

- In IT companies, use of e-HRM reduces the burden of HR staff and they can use the same time for other productive activities like strategic planning and development.

- e-HRM provides a transparent system as all information is centralized. The accuracy of information can be checked at any time by the IT employees.

- e-HRM can help to keep a better control over the various HR functions in IT industry. This is mainly because records of all activities are available online and can be accessed as per requirement.

\section{References}

Barrett, M., \& Oborn, E. (2013). Envisioning e-HRM and strategic HR: Taking seriously identity, innovative practice, and service. The Journal of Strategic Information Systems, 22, 252-256.

Bondarouk, T. V., \& Ruël, H. J. (2009). Electronic Human Resource Management: challenges in the digital era. The International Journal of Human Resource Management, 20(3), 505-514.

Dublin, L. (2004). The nine myths of e-learning implementation: ensuring the real return on your e-learning investment. Industrial and Commercial Training.

Galanaki, E. (2002). The decision to recruit online: A descriptive study. Career development international.

Gueutal, H. G., \& Falbe, C. M. (2005). Trends in Delivery Methods. The Professional Practice Series, 190.

Horton, W. K. (2001). Leading e-learning. American Society for Training and Development.

Kavanagh, M. J., Thite, M., \& Johnson, R. D. (2009). The Future of HRIS. Emerging Trends in HRM and IT.

Lakshmi, C. D. (2014). Study On E-Hrm Practices in Kovai Medical Center and Hospital, Coimbatore. Journal of Business Management \& Social Sciences Research (JBM\&SSR), 3(8), 43-47.

Majumdar, S. (2013). HCL's HR solution: trouble-ticketing. Business Standard. Retrieved from https://www.business-standard.com/article/opinion/shyamal-majumdar-hcl-s-hrsolution-trouble-ticketing-105070101024_1.html

Manju, S., \& Suresh, B. H. (2011). Training Design Interventions and Implications for the Productivity Effectiveness. Synergy, 9(1).

Marler, J. H., Liang, X., \& Dulebohn, J. H. (2006). Training and effective employee information technology use. Journal of Management, 32(5), 721-743. 
Nasreem, S., Hassan, M., \& Khan, T. A. (2016). Effectiveness of e-recruitment in small and medium enterprises of IT industry of Lahore (Pakistan). Pakistan Economic and Social Review, 54(1), 143-164.

Panneerselvem, A. (2017). Electronic human resource management, International journal of multidisciplinary research and modern education, 3(1), 55-58.

Patil, U. V. (2013). The Role of E-HRM in increasing positive work attitudes among it employees: with special reference to pune city, 1(3), 27-35.

Payne, S. C., Mendoza, A. M., \& Horner, M. T. (2018). Electronic Performance Management. The Brave New World of eHRM 2.0, 189.

Rahman, M. S., \& Hosain, M. S. (2021). E-HRM Practices for Organizational Sustainability: Evidence from Selected Textile Firms in Bangladesh. Asian Journal of Economics, Business and Accounting, 1-16.

Ruel, H. J., Bondarouk, T. V., \& Van der Velde, M. (2007). The contribution of e-HRM to HRM effectiveness: Results from a quantitative study in a Dutch Ministry. Employee relations, 29(3), 280-291.

Ruël, H., Bondarouk, T., \& Looise, J. K. (2004). E-HRM: Innovation or irritation. An explorative empirical study in five large companies on web-based HRM. Management revue, 364-380.

Sareen, P. (2015). Study of employee satisfaction towards e-HRM system. European Journal of Applied Business and Management, 1(1).

Sheeba Hamid (2011). A Study of Effectiveness of Training and Development Programmes of UPSTDC, India - An analysis, South Asian Journal of Tourism and Heritage, 4(1).

Sinha, B. C., \& Mishra, M. (2014). E-HRM tools: an empirical study in select Indian organizations. Indian Journal of Business and Management Invention, 3(9), 71-83.

Stone, D. L., \& Dulebohn, J. H. (2013). Emerging issues in theory and research on electronic human resource management (eHRM).

Strohmeier, S. (2007). Research in e-HRM: Review and implications, 17, 19-37. http://doi.org/10.1016/j.hrmr.2006.11.002

Strother, J. B. (2002). An assessment of the effectiveness of e-learning in corporate training programs. The International Review of Research in Open and Distributed Learning, 3(1).

Swaroop, K. R. (2012). E-HRM and how it will reduce the cost in organisation. Asia Pacific Journal of Marketing and Management Review, 1(4), 133-139.

Tyagi, S. K. (2012). A study and analysis of existence and involvements of computer assisted E-Learning techniques for the improvement and development of medical education and knowledge dissemination. International Journal of Management, IT and Engineering, 2(9), 381-93.

Voermans, M., \& van Veldhoven, M. J. P. M. (2007). Attitude towards E-HRM: an empirical study at Philips. Personnel Review, 36(6), 887-902.

\section{Author Biography}

Dr. Rupa Rathee is an Associate Professor in the Department of Management Studies, DCRUST, Murthal, Haryana (India). She has more than nineteen years of teaching experience to her credit. Her teaching and research area include Marketing and HRM. She has over fifty 
publications to her credit in reputed national and international journals of publishers like Emerald, Sage and Elsevier. She has contributed eight book chapters in the books of IGI Global, McGraw Hill Education and Palgrave Macmillan publishers. She has attended more than 30 FDPs at various prestigious institutes like IIM-Bangalore, IIM-Calcutta, IIMKozhikode, MDI-Gurgaon, IITM-Gwalior etc. She has contributed papers in over fifty national and international conferences. She has completed seven consultancy projects and one UGC (University Grants Commission) sponsored major research project.

Ms. Renu Bhuntel is Senior Research Fellow in the Department of Management Studies, DCRUST Murthal Sonepat (India). Her fields of interest include HRM and IT. She has over six publications to her credit in reputed international and UGC CARE listed journals. She has been awarded the best poster presentation at Global Innovator \& Researchers Conclave at DCRUST, Murthal. She has contributed papers in over nine international and national conferences. She has contributed two book chapters in international and national level. She has attended more than seventeen workshops and FDP and five webinars. 